\title{
ANÁLISE TEMPORAL DAS OCLUSIVAS ORAIS DO PORTUGUÊS EUROPEU: UM ESTUDO DE CASO DE NORMALIDADE E PERTURBAÇÃO FONOLÓGICA
}

\section{Temporal analysis of european portuguese stops: a case study of normality and phonologically disturbance}

\author{
Mário André Lopes Barroco ${ }^{(1)}$, Marta Teresa Pedrosa Domingues ${ }^{(2)}$, \\ Maria de Fátima Marques de Oliveira Pires ${ }^{(3)}$, Marisa Lousada ${ }^{(4)}$, Luis M. T. Jesus ${ }^{(5)}$
}

\begin{abstract}
RESUMO
Objetivo: neste artigo são analisadas as durações das diferentes fases das oclusivas produzidas por duas crianças, uma delas com perturbação fonológica (informante 2). Métodos: o corpus é constituído por 54 palavras com oclusivas em posição inicial, medial e final. Neste estudo participaram dois informantes nativos do Português Europeu (PE), com sete e oito anos de idade. Resultados: os resultados obtidos para o PE (informante 1) para a duração total das oclusivas mostram que a duração das oclusivas não vozeadas é superior a das oclusivas vozeadas. O Voice Onset Time (VOT) é, de forma geral, superior para as oclusivas não vozeadas, relativamente às oclusivas vozeadas. A informante 2 (com perturbação fonológica) efectua desvozeamento da oclusiva vozeada [g] em todas as posições de palavra e em posição inicial da oclusiva [d], vozeando-a em posição medial e final. A oclusiva [b] é normalmente vozeada. Conclusão: a maioria dos parâmetros analisados acompanhou a normalidade existindo excepções.
\end{abstract}

DESCRITORES: Acústica da Fala; Transtornos da Articulação; Fonoaudiologia

\section{INTRODUÇÃO}

O terapeuta da fala deve adquirir conhecimentos relativos aos padrões normais de produção de fala, principalmente ao nível das características acústicas, para posteriormente, poder avaliar e analisar as produções de indivíduos com perturbações de fala e delinear a intervenção mais apropriada às necessidades de cada indivíduo ${ }^{1}$.

As consoantes oclusivas caracterizam-se pela oclusão completa do tracto vocal provocando uma

(1) Terapeuta da Fala; Licenciado em Terapia da Fala pela Universidade de Aveiro, Portugal.

(2) Terapeuta da Fala; Licenciado em Terapia da Fala pela Universidade de Aveiro, Portugal.

(3) Terapeuta da Fala; Licenciado em Terapia da Fala pela Universidade de Aveiro, Portugal.

(4) Terapeuta da Fala e Professora na Universidade de Aveiro, Portugal; Mestre em Ciências da Fala e da Audição pela Universidade de Aveiro, Portugal.

(5) Professor na Universidade de Aveiro, Portugal; Doutorado em Electrónica pela University of Southampton, Reino Unido. interrupção momentânea da passagem de $\mathrm{ar}^{2}$. Tendo em conta esta característica, as consoantes oclusivas classificam-se de acordo com o local onde ocorre o bloqueio de ar (ponto de articulação). Desta forma, a oclusão pode ser bilabial /p, b/, alveolar/t, d/ e velar $/ \mathrm{k}, \mathrm{g} /$. As oclusivas também podem ser classificadas pela existência, ou não, de vibração das pregas vocais. Quando ocorre vibração, designam-se por vozeadas /b, d, g/. Nas não vozeadas/p, t, k/, não há vibração das pregas vocais ${ }^{3}$. Esta classificação, segundo o ponto de articulação e existência de vibração das pregas vocais, também é utilizada para as oclusivas do Português Europeu (PE) ${ }^{4}$.

O "Voice Onset Time" (VOT) é definido como sendo o tempo entre a "release", da constrição oral para a produção da oclusiva, e o início da vibração das pregas vocais ${ }^{5}$. O VOT é o principal parâmetro para a distinção entre oclusivas vozeadas e não vozeadas em sílaba inicial, para a língua inglesa. Esta característica temporal das oclusivas reflecte o "timing" complexo da coordenação supralaríngea-laríngea ${ }^{6}$. Além da informação acerca do vozeamento, também fornece informação acerca do ponto de articulação ${ }^{3}$. Permite distinguir as consoantes oclusivas bilabiais e 
dentais das consoantes velares, mas não permite distinguir entre bilabiais e dentais ${ }^{7}$.

Para as oclusivas do Inglês Americano os valores do VOT podem ser positivos, negativos ou zero. O seu valor é igual a zero quando a "release" e o início do vozeamento são simultâneos, menor que zero quando o vozeamento precede a "release", e maior que zero quando a "release" precede o vozeamento ${ }^{2,3}$.

Existem vários estudos ${ }^{2,3,5,7,8}$, em várias línguas, sobre o momento inicial do vozeamento relativamente à actividade supraglotal. As oclusivas vozeadas ${ }^{3}$ possuem valores do VOT que se encontram compreendidos entre $-20 \mathrm{~ms}$ e $+20 \mathrm{~ms}$. As oclusivas não vozeadas têm um intervalo de duração superior (compreendido entre 25 e 100 ms). A duração deste parâmetro para as oclusivas não-vozeadas é superior às oclusivas vozeadas ${ }^{2}$.

Num estudo ${ }^{7}$ em que se calculou o VOT para a posição inicial, verificaram-se valores positivos para as oclusivas não-vozeadas e valores negativos para as oclusivas vozeadas. Noutro estudo ${ }^{8}$ de oclusivas não vozeadas em discurso espontâneo e produção isolada, verificou-se que o VOT das bilabiais e dentais não era diferente na produção isolada. Verificou, também, que era semelhante para os vários pontos de articulação, em discurso espontâneo.

Num trabalho ${ }^{9}$ com crianças (5 a 17 anos) e adultos, onde se estudaram características das consoantes, tais como a duração e a variabilidade intrafalante, conclui-se que o VOT de /p/ e /t/ diminui ao longo da idade, até aos 15 anos. Esta é uma evidência de que, a coordenação articulatória das consoantes se torna mais adequada à medida que a criança se desenvolve. Num outro estudo ${ }^{6}$ sobre o vozeamento em posição inicial de oclusivas produzidas por crianças normais e de pré-termo, conclui-se que as crianças produzem valores do VOT mais apropriados para as oclusivas não vozeadas, do que para as vozeadas. Este facto pode estar relacionado com o aumento do controle neuromuscular e com uma actividade muscular mais complexa, necessários à manutenção do vozeamento durante a oclusão, especialmente nas oclusivas velares.

O papel do pré-vozeamento na distinção do vozeamento, em oclusivas em posição inicial foi também amplamente estudado ${ }^{10}$. O pré-vozeamento corresponde à vibração das pregas vocais durante a fase de fechamento, numa oclusiva em posição inicial. Para que ocorra vibração das pregas vocais é necessário que ocorram determinados processos fisiológicos e aerodinâmicos. A aquisição tardia de prévozeamento, nas crianças, pode ser devida a um tracto vocal relativamente curto. Verificou-se ${ }^{10}$ que o prévozeamento é influenciado pelo ponto de articulação da oclusiva, pela ocorrência, ou não, num grupo consonântico e pelo género do falante. Verificou-se ainda que, $25 \%$ de todas as oclusivas vozeadas, fo- ram produzidas sem pré-vozeamento. Relativamente ao ponto de articulação, as oclusivas bilabiais foram produzidas mais frequentemente com pré-vozeamento do que as alveolares. No entanto, não se verificaram diferenças na duração do pré-vozeamento.

Em Portugal, a informação existente sobre as consoantes oclusivas e as suas características é escassa, havendo no entanto um estudo ${ }^{11}$ sobre a duração total das oclusivas não vozeadas e vozeadas do Português Europeu. Concluiu-se ${ }^{11}$ que, as oclusivas não vozeadas apresentam uma duração superior às oclusivas vozeadas. Constatou-se ainda noutro trabalho ${ }^{12}$ que as oclusivas vozeadas apresentam durações de oclusão e de "release" menores do que as não vozeadas.

Num estudo ${ }^{13}$ envolvendo crianças com atraso de desenvolvimento da linguagem também se observaram diferenças nos parâmetros acústicos da fala específicos da língua. O estudo foi realizado com base na análise dos resultados obtidos referentes ao VOT, pois este permite classificar as consoantes oclusivas dentro da respectiva categoria fonética quanto ao vozeamento. O VOT foi medido com base nos espectrogramas das consoantes em posição inicial de sílaba.

Um outro estudo ${ }^{14}$, refere ainda que as alterações da maturação em função do tempo podem ser relatadas com o desenvolvimento de certos contrastes fonológicos da produção de fala, que podem ser encontrados com base no VOT e as diferentes durações de vogais que precedem as oclusivas vozeadas e não-vozeadas. Como cada criança não demonstrou contrastes fundamentais de vozeamento em todos os exemplares avaliados, no estudo, isto sugere uma aquisição gradual do comportamento esperado pelos adultos. Compararam-se ${ }^{14}$ também os resultados obtidos relativamente ao VOT, sendo o mesmo superior nos sujeitos com Perturbação Fonológica (PF) comparativamente aos sujeitos sem PF, e os sujeitos com PF apresentaram conjuntamente valores de VOT superiores nas oclusivas não-vozeadas do que nas oclusivas vozeadas, o que vai de encontro ao referido anteriormente relativo às características da normalidade neste parâmetro.

Tem-se verificado ${ }^{15}$ que crianças com PF produzem contrastes entre fones não padronizados, uma vez que estas são incapazes de processar todos os parâmetros acústicos do fone, pela imaturidade fisiológica ou porque todos os parâmetros são percepcionados como iguais. A análise ${ }^{16}$ dos parâmetros temporais relacionados com o contraste do vozeamento em posição inicial e final das consoantes oclusivas revela diferenças importantes na duração do vozeamento de crianças com PF e falantes normais. Em informantes normais, geralmente, existem valores distintos de VOT em consoantes oclusivas vozeadas e não vozeadas. As crianças com PF, por 
outro lado, têm realizações diversas. Um grupo demonstrou ter usado diferentes valores constrativos de VOT em consoantes oclusivas vozeadas e não vozeadas em posição inicial e um segundo grupo usou diferenças "exageradas" no contraste do VOT. Os resultados permitiram descrever erros de vozeamento produzidos pelas crianças com PF.

Num estudo ${ }^{17}$ sobre as consoantes oclusivas, verificou-se que os erros de produção das crianças resultam de um "colapso" com o contraste fonémico dos adultos que pode ser analisado acusticamente. Os resultados da análise fonológica mostram, por exemplo, o uso de alguns contextos de sons (e.g., posição inicial de palavra) mas não em outros (e.g., posição final de palavra), o que sugere um conhecimento incompleto da distribuição dos sons no modelo lexical dos adultos. Concluiu-se ${ }^{17}$ que o VOT pode ser um indicador da presença ou ausência de conhecimento produtivo nas primeiras palavras dos sujeitos, e pode ser utilizado como um indicador do conhecimento da criança com erros em posição velar.

Com este trabalho pretendeu-se comparar a duração das consoantes oclusivas produzidas por duas crianças (uma delas com perturbação fonológica), com trabalhos realizados anteriormente. Foi dada particular relevância à análise da duração da oclusão, VOT e duração total das oclusivas.

\section{MÉTODOS}

Neste estudo, participaram dois informantes de género feminino, naturais de Aveiro, falantes do PE. Uma informante de 8 anos e 7 meses a frequentar 0 $3^{\circ}$ ano de escolaridade sem alteração fonológica (informante 1) e outra com 7 anos e 6 meses de idade a frequentar $01^{\circ}$ ano de escolaridade com perturbação fonológica (informante 2).

Foi gravado um corpus, criado por Lousada e Jesus ${ }^{18}$, que contém 54 palavras reais (Tabela 1) com as oclusivas orais do PE/p, t, k, b, d, g/. O corpus é constituído por um igual número de palavras com consoantes oclusivas em posição inicial (seguidas das vogais /a, i, u/), medial (precedidas das vogais /a, i, u/ e seguidas da vogal /e/) e final (precedidas das vogais / $\mathbf{a}, a /$ ).

A informante 2 apresenta uma perturbação fonológica, uma vez que existe um problema de organização do seu sistema de sons ${ }^{19}$ (dificuldades em compreender contrastes de sons), utilizando o processo fonológico de desvozeamento. Este processo fonológico deve desaparecer, em posição final, aos 3 anos ${ }^{19}$. Num estudo ${ }^{20}$ na população portuguesa, é referido que este processo deveria desaparecer até aos 3 anos e 6 meses.

Na gravação, os informantes produziram palavras por repetição, inseridas na frase de apoio: "Diga (palavra) por favor". Não existem diferenças significati- vas entre os valores do VOT obtidos em discurso espontâneo e na repetição ${ }^{21}$. Desta forma os resultados obtidos por repetição podem ser comparados com os estudos onde a duração foi calculada em discurso espontâneo.

Os informantes encontravam-se colocados em frente a um microfone Philips SB C ME 400, unidireccional, localizado a $20 \mathrm{~cm}$ de distância da boca, encontrando-se ligado a um pré-amplificador Rane MS 1-b. O sinal acústico foi gravado em simultâneo com o sinal de electroglotografia (electroglotógrafo EG-PC3 produzido pela Tiger DRS, Inc. USA), usando um DAT Sony PCM-R 300 de 16 bits com uma frequência de amostragem de $48 \mathrm{kHz}$.

Para a segmentação das palavras, utilizou-se o programa Adobe Audition. Posteriormente, foi utilizado o Speech Filing System (SFS) para a anotação. Para a obtenção dos valores de duração, utilizou-se o programa Matlab.

\section{Realizaram-se as seguintes anotações ${ }^{18}$ :}

1. Início da vogal anterior, nas oclusivas em posição medial e final (IV1): início da segunda formante.

2. O final da vogal anterior e o início da oclusão nas oclusivas em posição medial e final (IO): final da segunda formante.

3. Início do pré-vozeamento contínuo até à "release" (IPV): início da vibração das pregas vocais, corresponde ao início de um sinal periódico de electroglotografia (EGG), quando as oclusivas estão em posição inicial e existe pré-vozeamento na oclusiva. É coincidente com o início da oclusão quando as oclusivas estão em posição medial ou final porque já existe vozeamento da vogal anterior.

4. Final do vozeamento da vogal anterior (FV): final da vibração das pregas vocais, corresponde ao final do sinal acústico periódico e a um sinal de EGG de amplitude igual a zero. Este parâmetro é igual a zero (não é considerado no cálculo das durações) quando não é observado.

5. Final do pré-vozeamento contínuo até à "release" (FPV): É coincidente com a anotação seguinte. Este parâmetro é igualado a zero (não é considerado no cálculo das durações) quando não é observado.

6. Final da oclusão e início da "release" (IR): foi definido como sendo o início do "burst". Para os casos com múltiplos "bursts", foi escolhido o de maior intensidade, que pode ser visualizado por um pico abrupto na forma de onda do sinal e uma barra vertical de ruído no espectrograma. No caso de não existir o "burst" foi definido como o início do ruído.

7. a. Final da "release" nas oclusivas em posição final (FR): fim do ruído; ou 7.b. final da "release" e início da vogal seguinte nas oclusivas em posição 
inicial e medial (FR): início da segunda formante.

8. Final da vogal seguinte nas oclusivas em posição inicial e medial (FV2): final da segunda formante.

Nos ficheiros de anotação foram ainda registados a posição de palavra (inicial, medial e final) e o vozeamento com os seguintes critérios ${ }^{22}$ :

Quando o sinal acústico ou o sinal de electroglotografia não apresentam uma estrutura periódica a oclusiva foi considerada não vozeada.

Quando a duração do pré-vozeamento é <1/ 3 do intervalo de oclusão, a oclusiva designa-se por desvozeada.

Quando a duração do pré-vozeamento está entre $1 / 3$ e 1/2 do intervalo de oclusão, a oclusiva designa-se por parcialmente desvozeada.

Quando a duração do pré-vozeamento é $>1 / 2$ do intervalo de oclusão, a consoante designa-se por vozeada.

\section{As seguintes durações foram analisadas:}

1. Duração da V1: IO - IV1

2. Duração do vozeamento durante a oclusão: FV - IO (para oclusivas em posição medial e final)

3. Duração do pré-vozeamento: FPV - IPV

4. Duração da oclusão: IR - IO

5. VOT: 1) FR - IR (no caso das oclusivas não vozeadas, das oclusivas desvozeadas e das oclusivas parcialmente desvozeadas) ou 2) IPV - IR (no caso das oclusivas vozeadas)

6. Duração da "release": FR - IR

7. Duração da V2: FV2 - FR

8. Duração total das oclusivas: FR - IO

\section{RESULTADOS}

A informante 1 apenas desvozeia as oclusivas vozeadas em posição final de palavra, devido, provavelmente, aos efeitos de coarticulação. A informante 2 desvozeia a oclusiva vozeada [g] em qualquer posição (inicial, medial e final). Realiza desvozeamento em posição inicial na produção da oclusiva [d], vozeando-a em posição medial e final (Tabela 2). Relativamente à oclusiva vozeada [b], a informante 2 realiza o seu vozeamento apesar de este ser por vezes parcialmente desvozeado.

Relativamente à informante 1 , na posição inicial o VOT nas oclusivas não vozeadas varia entre 0 e 100 $\mathrm{ms}$, verificando-se um aumento ao longo do contexto VOT[a]>VOT[i]>VOT[u]. Para as oclusivas vozeadas apenas foi possível calcular o VOT para [g] cuja duração foi de -29 ms. Para a informante 2 , os valores do VOT nas oclusivas não vozeadas são semelhantes aos das oclusivas vozeadas excepto para a oclusiva [b] que apresenta valores de VOT negativos. Na posição medial (ver Figura 1) as oclusivas vozeadas [d, g] da informante 1 apresentam valores de VOT negativos nas palavras "Buda" e "vaga". Estas oclusivas foram produzidas com vozeamento durante a oclusão. Para os restantes exemplos de [d] e [g] e para as três palavras com a oclusiva [b], o VOT não foi calculado porque não se identificou o IR. As oclusivas não vozeadas produzidas em posição medial pela informante 1, têm valores de VOT entre 0 e 50 ms. Para a informante 2 , os valores variam entre 0 e $25 \mathrm{~ms}$. Na posição final, para as oclusivas vozeadas, apenas se determinou o VOT nas oclusivas [d] e [g] com uma duração de -21 ms e -60 ms, respectivamente. Para as restantes oclusivas vozeadas e não vozeadas não foi possível anotar os parâmetros que permitem calcular o VOT para ambas as oclusivas.

De uma forma geral, o VOT das oclusivas não vozeadas é superior ao das oclusivas vozeadas, para todas as posições, para ambos os informantes. Verifica-se a influência do ponto de articulação no VOT das oclusivas não-vozeadas produzidas pela informante 1. A oclusiva [k] apresenta valores de VOT superiores a [t], e [t] valores maiores do que [p].

A duração da oclusão da informante 1 nas oclusivas não vozeadas é superior à duração das oclusivas vozeadas, em todas as posições. Aduração da oclusão, nas várias posições, varia entre os 30 e 180 ms. Os resultados obtidos para a informante 2 demonstram que a duração da oclusão nas oclusivas não vozeadas é superior à duração das oclusivas vozeadas apenas em posição medial (Figura 2) e final.

Para a informante 1 , na posição medial, as oclusivas vozeadas e não vozeadas têm valores de duração da vogal anterior (V1) semelhantes. Quando as oclusivas estão em posição final (Figura 3) a duração da V1 é superior, à posição medial. A vogal anterior foi mais curta quando seguida de uma oclusiva não vozeada do que quando seguida de uma oclusiva vozeada. Os resultados obtidos para a informante 2 mostram que, em posição medial, a duração da V1 é menor no contexto das consoantes oclusivas [d] e [g], e maior no contexto da oclusiva não-vozeada [p]. A duração maior é a da vogal [a]. Em posição final (ver Figura 3), a duração da V1 é geralmente superior quando precedida de oclusivas vozeadas. É de salientar que a duração da V1 é claramente superior no contexto da oclusiva [d].

Em relação à duração do vozeamento durante a oclusão, [p, t, k] apresentam uma curta duração, semelhante em todas as posições (Figura 4). Os valores estão compreendidos entre 0 e $50 \mathrm{~ms}$. Para as oclusivas vozeadas, não foi possível calcular a duração do vozeamento durante a oclusão, dada a impossibilidade de identificar o FV. Relativamente às oclusivas, em posição final, produzidas pela informante 2 , a duração é maior nas oclusivas vozeadas, excepto para as bilabiais e velares cuja duração é maior quando a vogal que as precede é o [a], tal como pode ser observado na Figura 4. 
Para a informante 1, não foi possível anotar o final de pré-vozeamento. A duração do pré-vozeamento da informante 2 só foi registada para a oclusiva [b] em posição inicial. Quando a oclusiva é precedida pela vogal [i] apresenta o valor mais alto. Na posição medial e final não foi possível calcular a duração do prévozeamento.

Para a informante 1, a duração da vogal seguinte (V2), apenas foi calculada para as posições inicial (Figura 5) e medial. Na posição inicial a duração de V2 precedida por oclusivas vozeadas e não vozeadas é semelhante, estando os valores compreendidos entre 50 e 200 ms. A duração da vogal [a] é a maior. Na posição medial, a duração da V2 é semelhante quando precedida por oclusivas vozeadas e não vozeadas (entre 0 e $100 \mathrm{~ms}$ ), excepto para o contexto da oclusiva [b] (entre 50 e $150 \mathrm{~ms}$ ). Para a informante 2, a duração da V2 é geralmente superior no contexto das oclusivas não-vozeadas, em posição inicial, com excepção para as oclusivas vozeadas [b] e [d] quando são precedidas pela vogal [i]. A duração da vogal seguinte é normalmente superior na vizinhan- ça de oclusivas vozeadas em posição medial e final, com excepção para vogais no contexto da oclusiva não-vozeada [k].

A duração total das oclusivas da informante 1, para a posição inicial, apresenta uma grande dispersão de valores (entre 50 e $300 \mathrm{~ms}$ ). As oclusivas em posição medial apresentam valores entre 50 e $150 \mathrm{~ms}$, tal como pode observado na Figura 6 . Não foi possível obter valores para a posição final dada a impossibilidade de anotar o final da "release". Para as posições inicial e medial, verifica-se que as oclusivas vozeadas têm uma duração menor do que as oclusivas não vozeadas (Figura 6). Relativamente à informante 2 (para oclusivas em posição medial e final), verificase que as oclusivas não vozeadas têm uma duração maior do que as vozeadas apesar de, em posição medial (Figura 6), a oclusiva vozeada [g] apresentar uma duração ligeiramente superior à oclusiva nãovozeada [k] quando precedida pela vogal [a].

$\mathrm{Na}$ Tabela 3 pode observar-se um resumo com os resultados das diferentes durações, para os dois informantes.

\section{Tabela 1 - Corpus de consoantes oclusivas}

Oclusiva bilabial /p/

\begin{tabular}{cl}
\hline \hline Palavra & \multicolumn{1}{c}{ IPA } \\
\hline \hline Pato & ['patu] \\
Pico & ['piku] \\
Pufo & ['pufu] \\
\hline Napa & ['nape] \\
Ripa & ['ripe ] \\
Lupa & ['lupe ] \\
\hline Top & ['ToP] \\
Pape & ['Pap] \\
Tape & ['tap] \\
\hline \hline
\end{tabular}

Oclusiva bilabial /b/

\begin{tabular}{cl}
\hline \hline Palavra & IPA \\
\hline \hline Bato & ['batu] \\
Bico & ['biku] \\
Bufo & ['bufu] \\
\hline Naba & ['nabe $]$ \\
Chiba & ['Sibe $]$ \\
Juba & ['3ube $]$ \\
\hline Sobe & ['sob] \\
Sabe & ['sab] \\
Cabe & ['kab] \\
\hline \hline
\end{tabular}

Oclusiva alveolar /t/

\begin{tabular}{|c|c|}
\hline Palavra & IPA \\
\hline Tacto & ['tatu] \\
\hline Tica & ['tik e] \\
\hline Tuna & ['tun $\boldsymbol{\varepsilon}]$ \\
\hline Nata & ['nat e] \\
\hline Rita & ['rit e ] \\
\hline Luta & ['lute] \\
\hline Pote & ['pot ] \\
\hline Bate & ['bat] \\
\hline Date & ['dat] \\
\hline
\end{tabular}

Oclusiva alveolar/d/

\begin{tabular}{cl}
\hline \hline Palavra & \multicolumn{1}{c}{ IPA } \\
\hline \hline Dato & ['datu $]$ \\
Dica & ['dike ] \\
Duna & ['dune $]$ \\
\hline Nada & ['nade $]$ \\
Vida & ['vide $]$ \\
Buda & ['bude $]$ \\
\hline Pode & ['pod] \\
Nade & ['nad] \\
Jade & ['3ad] \\
\hline \hline
\end{tabular}

Oclusiva velar $/ \mathrm{k} /$

\begin{tabular}{cl}
\hline \hline Palavra & IPA \\
\hline \hline Cacto & ['katu] \\
Quita & ['kite ] \\
Cume & ['kum] \\
\hline Vaca & ['vace] \\
Pica & ['pike] \\
Nuca & ['nuke] \\
\hline Roque & ['rok] \\
Saque & ['sak] \\
Taque & ['tak] \\
\hline \hline
\end{tabular}

Oclusiva velar/g/

\begin{tabular}{cl}
\hline \hline Palavra & \multicolumn{1}{c}{ IPA } \\
\hline \hline Gato & ['gatu] \\
Guita & ['gita] \\
Gume & ['gum] \\
\hline Vaga & ['vage ] \\
Viga & ['vige ] \\
Guga & ['guge] \\
\hline Rogue & ['rog] \\
Pague & ['pag] \\
Vague & ['vag] \\
\hline \hline
\end{tabular}


Tabela 2 - Classificação do tipo de vozeamento das oclusivas, produzidas pelos informantes, nas diferentes posições de palavra. (1) parcialmente desvozeada, (2) Vozeada e (3) desvozeada

\begin{tabular}{c|c|c|c|c|c|c|c}
\hline \multirow{2}{*}{ Posição de palavra } & Oclusiva & \multicolumn{2}{|c|}{ [b] } & \multicolumn{2}{c|}{ [d] } & \multicolumn{2}{c}{ [g] } \\
\cline { 2 - 8 } & $\begin{array}{c}\text { Informante } \\
\text { Palavra }\end{array}$ & Inf. 1 & Inf. 2 & Inf. 1 & Inf. 2 & Inf. 1 & Inf. 2 \\
\hline \multirow{3}{*}{ Inicial } & $1^{\mathrm{a}}$ & 3 & 3 & 3 & 1 & 3 & 1 \\
& $2^{\mathrm{a}}$ & 3 & 3 & 3 & 1 & 3 & 1 \\
& $3^{\mathrm{a}}$ & 3 & 3 & 3 & 1 & 3 & 1 \\
\hline \multirow{3}{*}{ Medial } & $1^{\mathrm{a}}$ & 3 & 3 & 3 & 2 & 3 & 1 \\
& $2^{\mathrm{a}}$ & 3 & 3 & 3 & 2 & 3 & 1 \\
& $3^{\mathrm{a}}$ & 3 & 3 & 3 & 2 & 3 & 1 \\
\hline \multirow{3}{*}{ Final } & $1^{\mathrm{a}}$ & 1 & 3 & 1 & 2 & 1 & 1 \\
& $2^{\mathrm{a}}$ & 1 & 3 & 1 & 2 & 1 & 1 \\
& $3^{\mathrm{a}}$ & 1 & 1 & 1 & 2 & 1 & 1 \\
\hline
\end{tabular}
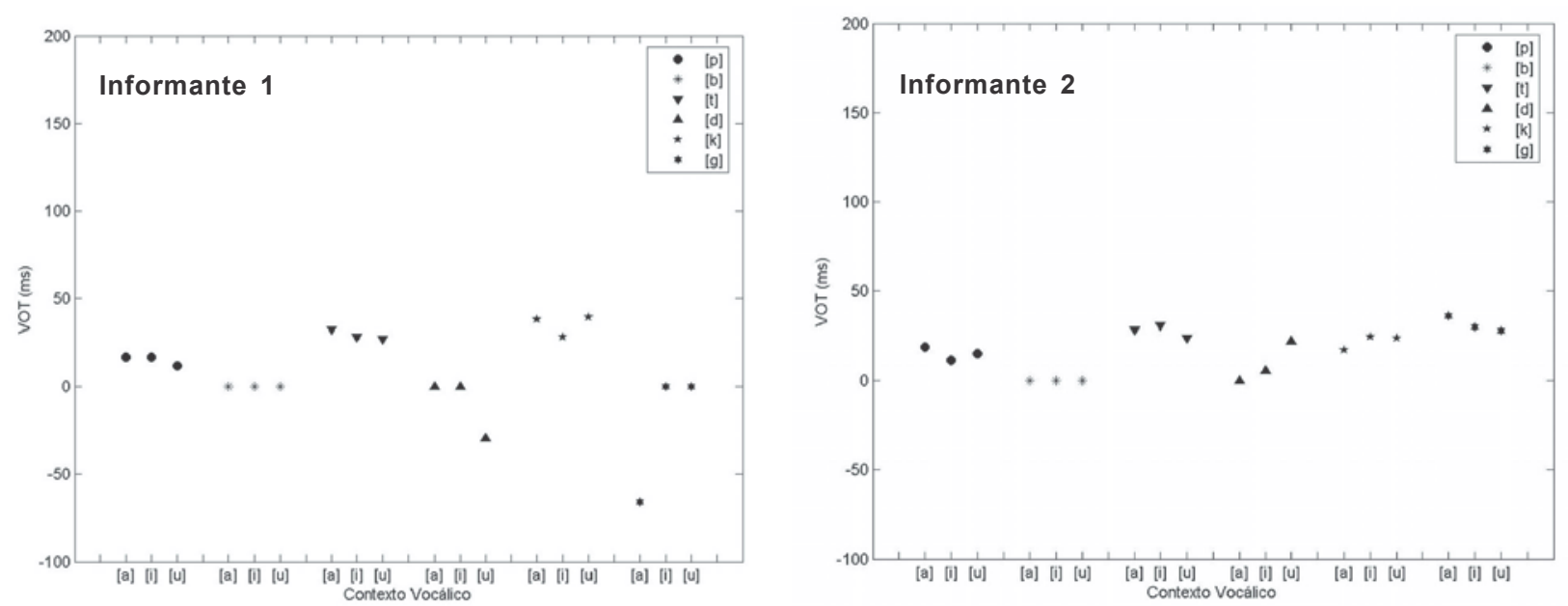

Figura 1 - VOT em posição medial de palavra
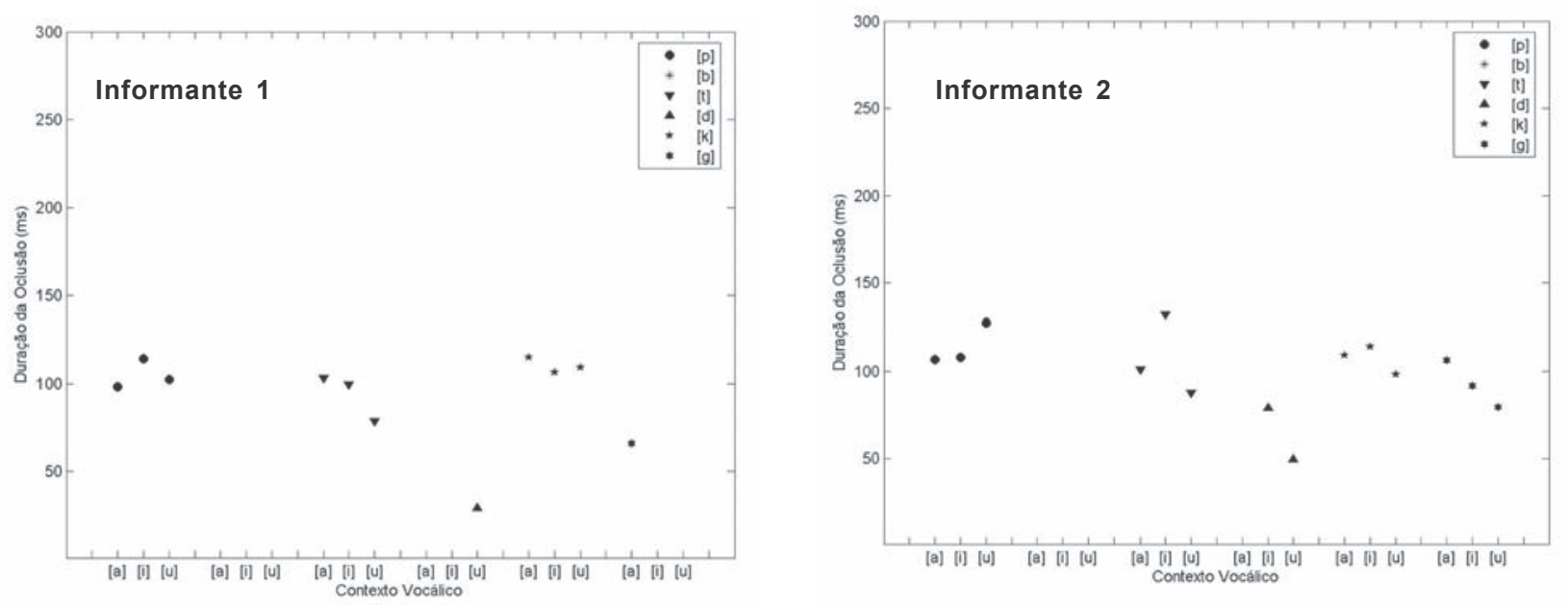

Figura 2 - Duração da oclusão em posição medial de palavra 

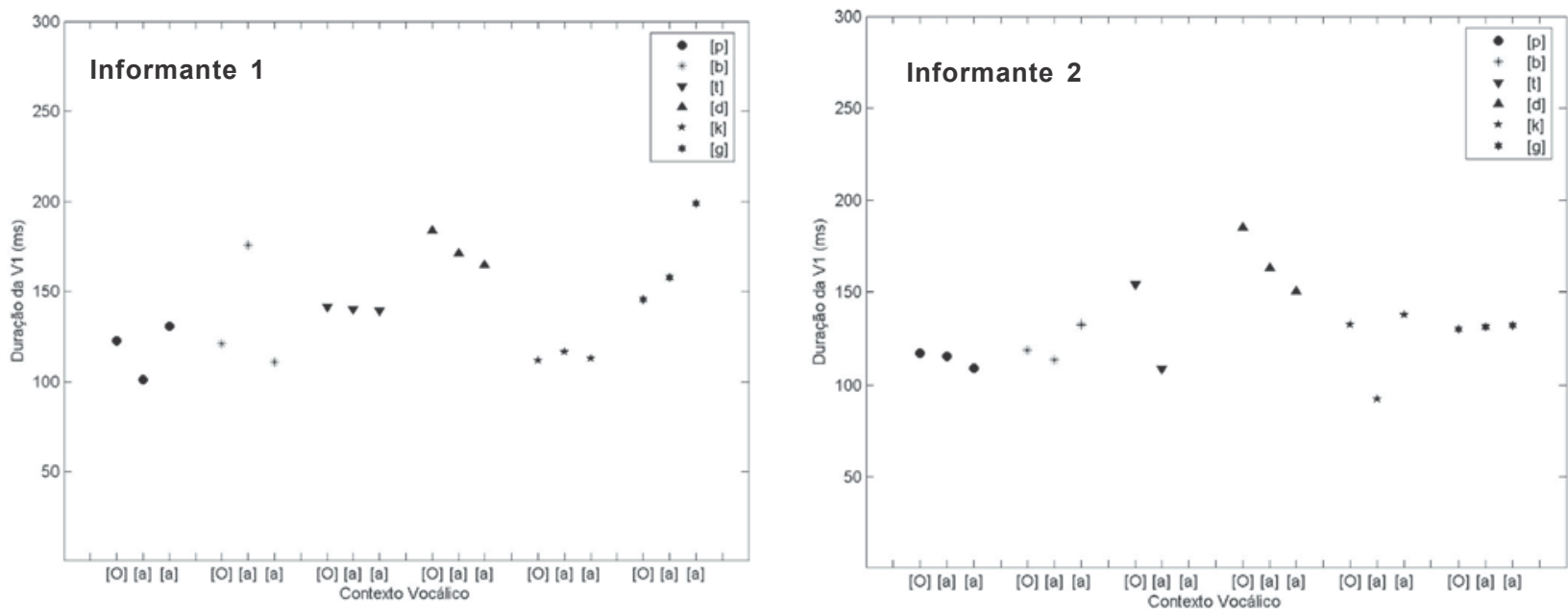

Figura 3 - Duração da V1 em posição final de palavra
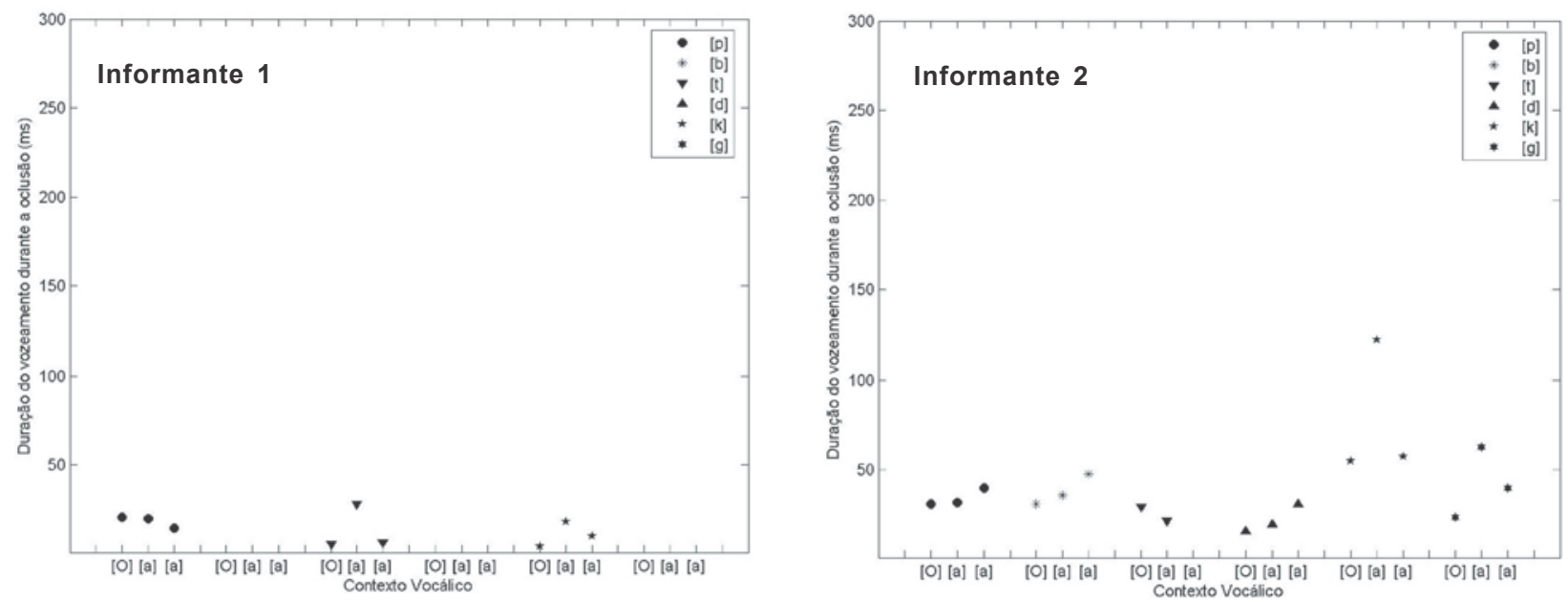

Figura 4 - Duração do vozeamento durante a oclusão em posição final de palavra
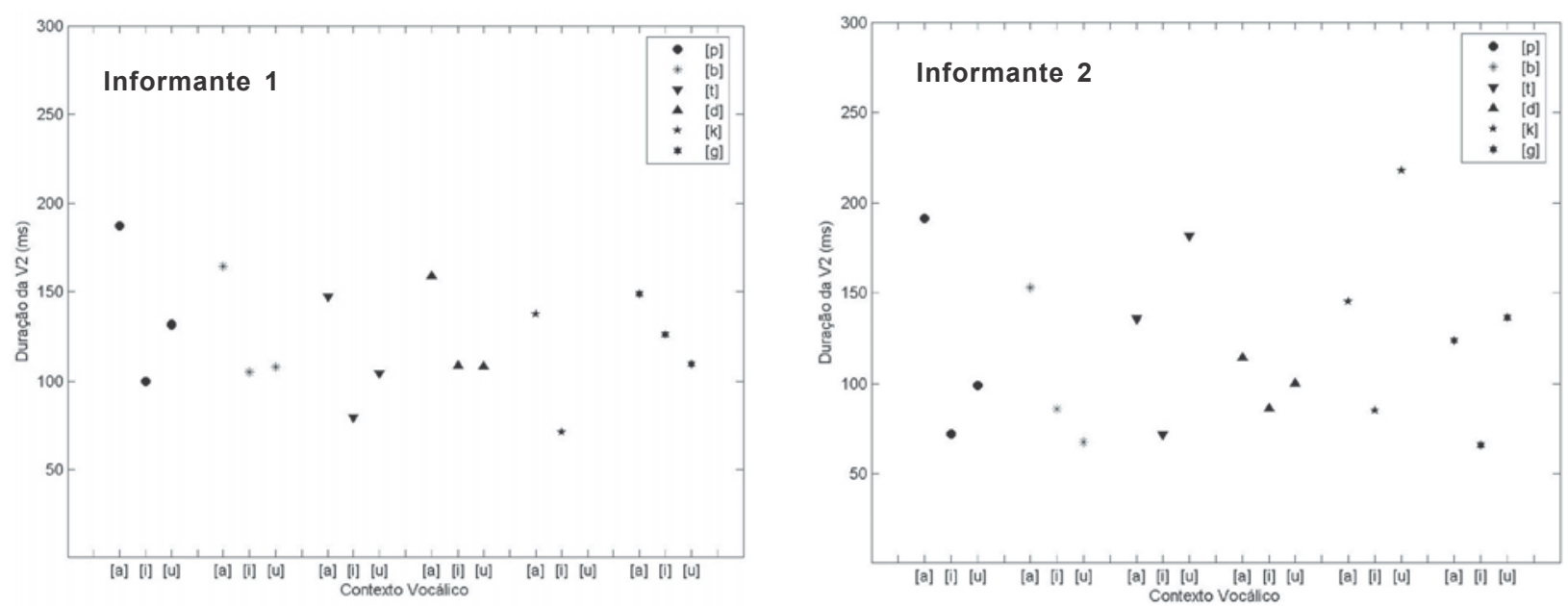

Figura 5 - Duraçāo da V2 em posiçāo inicial de palavra 

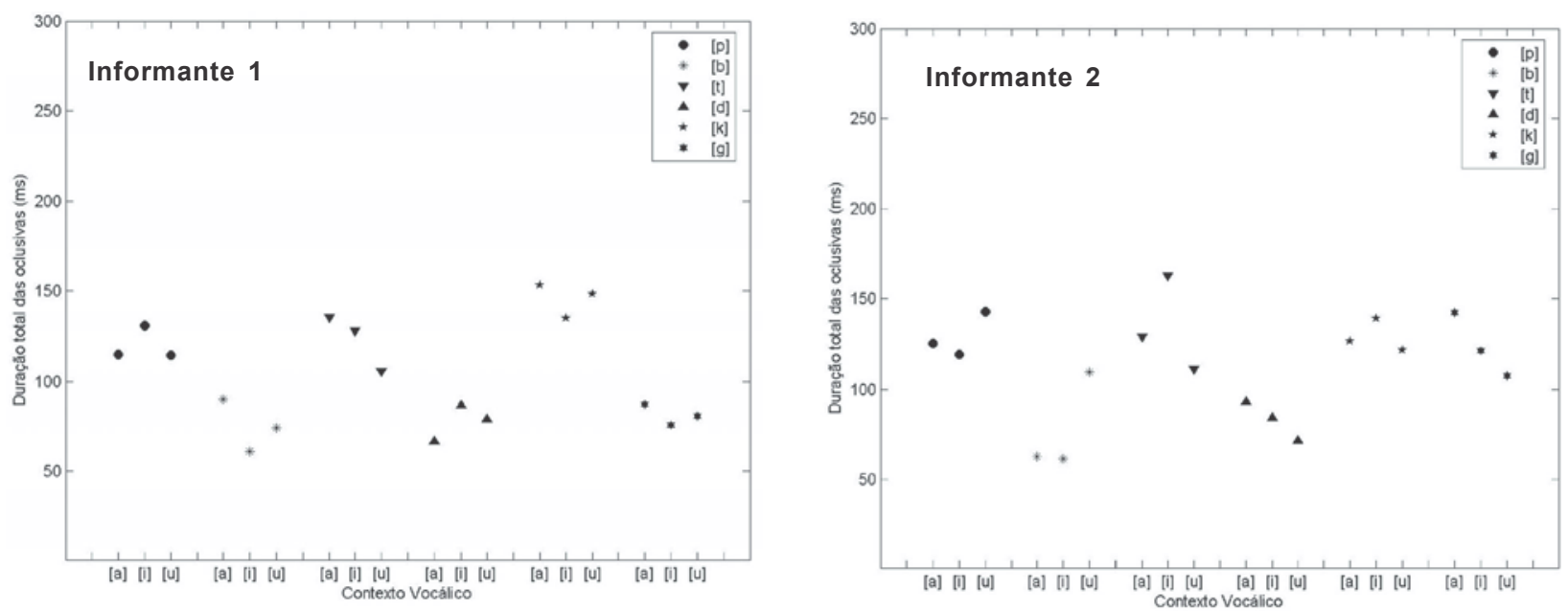

Figura 6 - Duração total das oclusivas em posição medial de palavra

Tabela 3 - Valores médios das diferentes durações para os dois informantes

\begin{tabular}{ccc|cc|cc|cc|cc|cc}
\hline Oclusiva & \multicolumn{2}{c|}{$[\mathrm{p}]$} & \multicolumn{2}{c|}{$[\mathrm{b}]$} & \multicolumn{2}{c|}{$[\mathrm{t}]$} & \multicolumn{2}{c|}{$[\mathrm{d}]$} & \multicolumn{2}{c|}{$[\mathrm{k}]$} & \multicolumn{2}{c}{$[\mathrm{g}]$} \\
\hline Informante & 1 & 2 & 1 & 2 & 1 & 2 & 1 & 2 & 1 & 2 & 1 & 2 \\
Dur. V1 (ms) & 99 & 112 & 108 & 112 & 130 & 114 & 117 & 140 & 109 & 105 & 138 & 122 \\
Dur. voz oclusão (ms) & 17 & 26 & -- & 30 & 18 & 30 & -- & 21 & 16 & 54 & -- & 35 \\
Dur. oclusão (ms) & 125 & 58 & -- & 135 & 115 & -- & 25 & 203 & 108 & 66 & 52 & 5 \\
VOT (ms) & 26 & 24 & 174 & 106 & 31 & 18 & 148 & 217 & 50 & 10 & 240 & 563 \\
Dur. V2 (ms) & 222 & 89 & 119 & 121 & 83 & 90 & 959 & 91 & 72 & 80 & 98 & 88 \\
Dur. total (ms) & 150 & 34 & 81 & 71 & 160 & 178 & 76 & 22 & 162 & 56 & 87 & 38 \\
\hline
\end{tabular}

\section{DISCUSSÃO}

Analisando os resultados obtidos para a duração total das oclusivas, em ambos os informantes, verifica-se que estes vão de encontro aos dados apresentados em estudo ${ }^{11}$. Deve-se no entanto ter em conta que a presente pesquisa inclui apenas dois informantes, o que não permite generalizar os resultados para a população portuguesa. Comparando a duração total das oclusivas em crianças, dados obtidos neste trabalho, e a duração em adultos, constatou-se que em ambos a duração das oclusivas não vozeadas é superior à duração das oclusivas vozeadas.

Verificou-se num estudo ${ }^{9}$ anterior que, para as idades compreendidas entre 7 e 9 anos, a duração total das oclusivas varia entre 110 e $130 \mathrm{~ms}$. Os resultados obtidos para o PE (informante 1) são mais variáveis: a duração total das oclusivas varia entre 50 e 300 ms, na posição inicial, e entre 50 e 150 ms para a posição medial.

Os valores do VOT encontrados em diversos trabalhos $2,3,5,7,8$, mostram que, de forma geral, as oclusivas não vozeadas apresentam uma duração superior relativamente às oclusivas vozeadas, podendo estas últimas possuir valores negativos. Neste estudo, verificou-se que para ambos os informantes, o VOT varia da mesma forma. Estes resultados vão de encontro aos estudos sobre o VOT consultados. Comparando os resultados obtidos neste trabalho, em posição inicial, com outro estudo ${ }^{7}$ verifica-se que as oclusivas não vozeadas têm um VOT entre 0 e 100 $\mathrm{ms}$ e no trabalho apresentado $\mathrm{em}^{7}$ os valores estão compreendidos entre 41 e $69 \mathrm{~ms}$. Estes resultados mostram a semelhança na duração do VOT para, a posição inicial de oclusivas não vozeadas. Em pesquisa ${ }^{9}$ anterior foram observados para as oclusivas [p] e [t] valores do VOT entre 90 e $110 \mathrm{~ms}$. Verifica-se que o VOT é inferior para o PE (entre 25 e $35 \mathrm{~ms}$ ). Relativamente ao VOT em posição medial, para as oclusivas não vozeadas os valores obtidos estão de acordo com outros estudos ${ }^{3}$.

Para as oclusivas vozeadas, em posição medial e final, os valores de VOT obtidos para o PE, são inferiores aos referidos ${ }^{3}$ para o Inglês, estando, os deste trabalho, entre $-21 \mathrm{~ms} \mathrm{e} \mathrm{-}-60 \mathrm{~ms}$, e entre -20 e $20 \mathrm{~ms}$ no livro ${ }^{3}$.

Outros autores ${ }^{13}$ afirmam existir uma relação entre o desenvolvimento da criança e o VOT. Talvez seja esta a razão pela qual as oclusivas vozeadas têm valores, em módulo, superiores aos valores apresentados em em outro estudo ${ }^{3}$.

O VOT possui uma relação com o ponto de articulação das oclusivas não vozeadas ${ }^{3}$, ou seja, o VOT aumenta consoante a posteriorização das oclusivas. Desta 
forma, espera-se que o VOT seja maior nas oclusivas velares. Os resultados obtidos neste trabalho estão em conformidade com esta afirmação, pois também se verificam valores superiores de VOT nas oclusivas velares.

Segundo a literatura ${ }^{3}$, a duração da oclusão varia entre 50 e $150 \mathrm{~ms}$. De uma forma geral, os resultados obtidos estão em conformidade com os referidos anteriormente. O intervalo de duração obtido neste trabalho está compreendido entre o 30 e $180 \mathrm{~ms}$.

Observou-se que na informante 2 só existe prévozeamento na oclusiva vozeada [b], em posição inicial de palavra seguida de vogal.

Para a posição medial e final, existem diferenças na duração da V2 entre os informantes.

Um parâmetro determinante na percepção das oclusivas vozeadas e não vozeadas poderá ser a duração total. Quando comparadas as durações totais das oclusivas não vozeadas e vozeadas verifica-se que a duração total é superior nas oclusivas não vozeadas relativamente às vozeadas o que está de acordo com a normalidade ${ }^{11}$.

Em trabalhos futuros será pertinente estender o estudo a um número superior de informantes de ambos os géneros para verificar se ocorrem as mesmas alterações e verificar a variação das medidas acústicas ao longo do tempo em estudos longitudinais. Será também interessante realizar gravações de informantes que utilizem outros processos fonológicos, tais como, processos de anteriorização, posteriorização, fricatização, vozeamento de consoantes oclusivas pré-vocálicas e assimilação.

\section{CONCLUSÃO}

Com a realização deste trabalho foi possível comparar a duração das consoantes oclusivas com trabaIhos realizados anteriormente. Trata-se no entanto de um estudo de caso de dois informantes que deve ser generalizado com algumas reservas. As medidas comparadas com outros estudos foram a duração da oclusão, o VOT e a duração total das oclusivas.
Para a duração da oclusão verificou-se uma semelhança entre os valores obtidos e os valores apresentados nos estudos consultados. Relativamente ao VOT e à duração total das oclusivas observa-se que a duração é superior para as oclusivas não vozeadas, em todas as posições.

O desenvolvimento e maturação das estruturas do aparelho fonador influenciam as medidas acústicas. Com a realização deste trabalho verificou-se conformidade entre os resultados obtidos, na produção dos informantes, e os resultados observados, nos vários estudos para as produções da população adulta.

Os resultados obtidos neste estudo são importantes para a intervenção em terapia da fala, uma vez que, face ao que foi analisado poderá ser adaptado a intervenção às necessidades da criança e ajudar a ultrapassar as suas dificuldades dando-lhe o "feedback" do que necessita de alterar/adaptar durante a produção das oclusivas desvozeadas para as mesmas passarem a ser vozeadas.

Como foi observado, a informante 2 desvozeou a oclusiva [d] em posição inicial e vozeou-a em posição medial e final. É de salientar que as oclusivas foram produzidas em palavras dissilábicas, que em posição inicial a oclusiva estava inserida na sílaba tónica e em posição medial e final a oclusiva estava inserida na sílaba átona. Os resultados obtidos relativamente à oclusiva [d] vêm confrontar a intervenção realizada em terapia da fala, uma vez que, esta se apoia, para a redução deste processo fonológico (desvozeamento), na utilização de pares de palavras que contêm as oclusivas vozeadas e não-vozeadas inseridas em sílabas tónicas dissilábicas, para facilitar a sua discriminação e produção. No entanto, essa característica pode não ser aplicada a todas as crianças e será necessário adequar a intervenção conforme as necessidades e características pessoais da criança com que se está a trabalhar.

\section{AGRADECIMENTO}

Este trabalho foi desenvolvido no âmbito da disciplina semestral de Projecto (2005/2006) da Licenciatura em Terapia da Fala, Universidade de

\section{ABSTRACT}

Purpose: this paper submits a study on the duration of the different phases of stops produced by two children, one of them with phonological disturbance (speaker 2). Methods: the corpus includes 54 real words, with stop consonants in initial, medial and final position. In this study two of European Portuguese (EP) native speakers, aged between seven and eight years, took part. Results: the results for the EP speaker 1 showed that the total duration of voiceless stop consonants was greater than voiced stop consonants. The VOT was, in general, larger for voiceless stops than in voiced stop consonant. Speaker 2 (with phonological disorder) devoiced the stop [g], and the stop consonant [d] was devoiced in initial position and voiced in medial and final position. The stop consonant [b] was normally voiced. Conclusion: most of the analyzed durations show similar values for both speakers.

KEYWORDS: Speech Acoustics; Articulation Disorders; Speech, Language and Hearing Sciences 
Aveiro, Portugal.

\section{REFERÊNCIAS}

1. Lousada M. Estudo da produção de oclusivas do português europeu. [mestrado]. Aveiro: Universidade de Aveiro; 2006.

2. Borden G, Harris K, Raphael L. Speech science primer: physiology, acoustics, and perception of speech. 4a ed. Baltimore: Lippincott, Williams \& Wilkins; 2003.

3. Kent R, Read C. The acoustic analysis of speech. 2a ed. Singular; 2002.

4. Mateus M, Falé I, Freitas M. Fonética e fonologia português. Lisboa: Universidade Aberta; 2005.

5. Lisker L, Abramson A. A cross-language study of voicing in initial stops: acoustical measurements. Word 1964; 20: 384-422.

6. Bortolini U, Zmarich C, Fior R, Bonifacio S. Wordinitial voicing in the productions of stops in normal and preterm Italian infants. Int $\mathrm{J}$ Pediatr Otorhinolaryngol. 1995; 31(2-3): 191-206.

7. Ögüt $F$, Kiliç $M$, Engin E, Midilli R. Voice onset time for turkish stop consonants. Speech Commun 2006; 48: 1094-9.

8. Gósy M. The VOT of the hungarian voiceless plosives in words and in spontaneous speech. Int $\mathrm{J}$ Speech Technol. 2001; 4, 75-85.

9. Gerosa M, Lee S, Giulian D, Narayanan S. Analyzing children's speech: an acoustical study of consonants and consonant-vowel transition. Acoust Speech Signal Process. 2006; 1, 393-6.

10. Alphen P, Smits R. Acoustical and perceptual analysis of the voicing distinction in dutch initial plosives: the role of pre-voicing. J Phonetics. 2004; 32: 455-91.

11. Veloso J. The role of consonantal duration and tenseness in the voicing distinctions of portuguese stops. Proceedings of the 13th International Congress of Phonetic Sciences; 1995; Stockholm, Sweden. p. 266-9.
12. Mendonça S. Oclusivas orais em discurso espontâneo: variação intra ou interpessoal. Actas do XII Encontro Nacional da Associação Portuguesa de Linguística; 1996; Braga-Guimarães.

13. Konefal J, Fokes J. Voice onset time: the development of spanish/english distinction in normal and language disordered children. J Phonetics 1981; 437-44.

14. Smit A, Bernthal J. Voicing contrasts and their phonological implications in the speech of articulationdisordered children. J Speech Hear Res. 1983; 26: 486-500.

15. Forrest K, Rockman B. Acoustic and perceptual analysis of word-initial stop consonants in phonologically disordered children. J Speech Hear Res. 1988; 31: 449-59.

16. Catts $\mathrm{H}$, Jensen $\mathrm{P}$. Speech timing of phonologically disordered children: voicing contrast of initial and final stop consonants. J Speech Hear Res. 1983; 26: 501-10.

17. Tyler A, Figurski R, Langsdale T. Relationships acoustically determined knowledge of stop place and voicing contrasts and phonological treatment progress. J Speech Hear Res. 1993; 36: 746-59.

18. Lousada M, Jesus L. Analysis of stop consonant production in european portuguese. Proceedings of the ISCA Workshop on Experimental Linguistics; 2006; Athens, Greece p. 177-180.

19. Bowen, C., Developmental phonological disorders: a practical guide for families and teachers. Melbourne: ACER Press; 1998.

20. Cambim, N., Processos fonológicos em crianças dos 3;06A aos 4;05A. [monografia]. Alcoitão: Escola Superior de Saúde do Alcoitão; 2002.

21. Bond Z, Korte S. Children's spontaneous and imitative speech: an acoustic-phonetic analysis. J Speech Lang Hear Res. 1983; 26: 464-7.

22. Jesus $L$, Shadle C. A parametric study of the spectral characteristics of european portuguese fricatives. J Phonetics. 2003; 30: 437-464.

\title{
RECEBIDO EM: 15/11/2006
}

ACEITO EM: 13/04/2007

\author{
Endereço para correspondência \\ Luis M. T. Jesus \\ Escola Superior de Saúde da Universidade de Aveiro (ESSUA) e \\ Instituto de Engenharia Electrónica e Telemática de Aveiro (IEETA) \\ Universidade de Aveiro \\ 3810-193 Aveiro \\ Portugal \\ Tel: +351234372458 \\ Fax: +351234401597 \\ E-mail: Imtj@essua.ua.pt
}

